Saudi Journal of Medicine

Abbreviated Key Title: Saudi J Med ISSN 2518-3389 (Print) |ISSN 2518-3397 (Online) Scholars Middle East Publishers, Dubai, United Arab Emirates

Journal homepage: https://saudijournals.com/sjm

Original Research Article

\title{
Risk Factors Associated With Acute Coronary Syndrome among Patients Admitted to the Coronary Care Unit in the Military Cardiac Center - Sana'a-Yemen
}

Dr. Ahmed Kaid Salem ${ }^{1 *}$, Dr. Nouradden Aljaber ${ }^{1}$, Dr. Akram Al-Haj ${ }^{2}$, Dr. Khairallah Abdulah Al-Matari ${ }^{3}$, Prof Amin Ablrub $^{1}$, Dr. Ali Ahmed Al-Zaazaai ${ }^{4}$

${ }^{1}$ Internal Medicine, Faculty of Medicine and Health Sciences -Sana'a University, Sana'a, Yemen

${ }^{2}$ Internal Medicine, Faculty of Medicine and Health Sciences -21 September University

${ }^{3}$ Military Cardiac Centre

${ }^{4}$ M.Sc. Clinical Pharmacy of China and Products Specialist with Al-Jabal Groups of Company in Yemen

DOI: $10.36348 /$ sjm.2020.v05i06.003

| Received: 03.06.2020 | Accepted: 12.06.2020 | Published: 18.06.2020

*Corresponding Author: Dr. Ahmed Kaid Salem

\section{Abstract}

Background: Acute coronary syndrome (ACS) refers to a spectrum of symptoms compatible with acute myocardial ischemia. Worldwide acute coronary syndrome (ACS) is one of the main reasons for hospital admission and the leading cause of death. Several risk factors have been identified. However high blood pressure and hypercholesterolemia remain the most important risk factors in (ACS). Objective: To determine the risk factors associated with ACS among patients admitted to the coronary care unit (CCU) in the Military Hospital-Sana'a. Methodology: Study design according to a case-control study. Two groups of patients were included in this study, the first group was cases who have (ACS), and the second group was control cases admitted to CCU for other causes. All data were recorded in a special sheet including demographic, clinical presentation, investigation, and treatment plan. The data was entered into PC and analyzed statistically. Results: There were 124 patients with ACS versus 91 control patients without ACS. The majority of participants in the two groups were males $(80 \%)$. Their age ranged from 18 to 95 years old with a mean age of 53.9 \pm 13.6 years. $(86.5 \%)$ of them were 40 years old or above. The significant risk factors associated with ACS were hypertension, Khat chewing found in $71.6 \%, 64.4 \%$, of the patients, respectively. Another significant risk factor was dyslipidemia which was higher among ACS patients than the control group with a P-value of $<0.05$. Conclusion: Preventing the program from avoiding risk factors that were associated with ACS may decrease the occurring of ACS and reduce the morbidity and mortality in Yemeni patients.

Keywords: Risk Factors, Acute Coronary Syndrome (ACS) Yemen.

Copyright @ 2020: This is an open-access article distributed under the terms of the Creative Commons Attribution license which permits unrestricted use, distribution, and reproduction in any medium for non-commercial use (NonCommercial, or CC-BY-NC) provided the original author and source are credited.

\section{INTRODUCTION}

Acute coronary syndrome (ACS) refers to a spectrum of symptoms compatible with acute myocardial ischemia. It is one of the main reasons for hospital admission in western countries and the leading cause of death worldwide [1-3]. In 2010, it was estimated that cardiovascular diseases (CVD) caused 16 million deaths despite, a considerable number of these causes that can be prevented [4].

The clinical types of ACS include unstable angina and acute myocardial infarction (AMI) with or without ST-segment elevation. Several modifiable risk factors for (ACS) have been identified, including; smoking, dyslipidemia, hypertension, and diabetes, with obesity and metabolic syndrome, are commonly involved [6].
The incidence of ACS in younger people is much lower than in older people, although the incidence varies depending on the population's age, habit, and social changes [7-10]. A recent study in Spain found that people younger than 45 years of age accounted only for $6 \%$ of all hospital admissions with (ACS) in men and only $2 \%$ in women. However, the rates of hospital readmission were significantly higher among young ages than in the population in which the first event occurred at later ages [11].

Moreover, patients who have ACS at an early age are at risk for many potential years of life lost, and their post-event survival translates as substantial costs in terms of health and social resources consumed [12]. Like in other parts of the developing countries, the population in Yemen is progressively changing, resulting in increased admission of middle-aged 
individuals and elderly with complicated cardiac diseases [13].

In recent decades there have been important changes in the exposure to risk factors for ACS, such as the increased prevalence of sedentary lifestyles, obesity, metabolic syndrome, and diabetes mellitus. Tobacco and obesity remain important contributors as well [14, 15].

Studies tailored to detect risk factors among Yemeni patients with (ACS) are lacking. Therefore this study was taken to determine possible risk factors in Yemeni patients presented into Cardiac Centre in the Military Hospital with ACS. Our objective to study the risk factors associated with acute coronary syndrome among Yemeni patients admitted to the coronary care unit in the Military Hospital - Sana'a Yemen. Also to determine the factors associated with ACS among cases in comparison to controls. As well as to assess mortality among cases in comparison to controls.

\section{MATERIALS AND METHOD \\ Study location}

The study took place in the CCU of the Cardiac Military Centre in Sana'a city - Yemen. The Coronary Care Unit (CCU) in this hospital is well equipped with the sophisticated system and intensive care machines and instruments. It is considered one of the most advanced governmental cardiac center in the country. In 2019, five hundred and sixty (560) cardiac patients were treated for ACA.

\section{Study Design}

This study was a case-control study. It involved cases admitted to $\mathrm{CCU}$ with Acute coronary syndrome. Matching case-control were selected from cases admitted to the coronary care unit (CCU) for other medical diseases. Odds ratio (OR) was used as the outcome measure of association.

\section{Study Population and recruitment}

All patients who were admitted to the coronary care unit of the cardiac center in the Military Hospital in Sana'a with the diagnosis of ACS during January, $1^{\text {st }}$ $30^{\text {th }}$ June 2019. Were enrolled as cases. Matched controls were then selected from the CCU and cardiac department at the cardiac center but without a diagnosis of ACS or IHD. Age and sex matching aids in the elimination of confounding effects of age and sex in addition to providing optimal controls for neutral comparison.

\section{Inclusion Criteria}

All adult patients with the diagnosis of ACS who meet the case definition. The case definition of ACS was patients who have at least two of the following criteria include Typical chest pain, ECG changes, and Positive cardiac enzymes.

ST-segment elevation myocardial infarction (STEMI) consists of chest pain, ST-segment elevation on ECG, and elevated cardiac enzymes. Non-STsegment elevation myocardial infarction (NSTEMI) consists of chest pain, ST segment depression, and elevated cardiac enzymes. Unstable angina (UA) consists of chest pain, ST-segment depression, and normal cardiac enzymes. Patients with chronic inflammatory conditions e.g. systemic lupus erythematous is, rheumatoid arthritis, or vasculitis and patients younger than 18 years old were excluded from the study.

\section{Data Collection}

Special questionnaires were designed to document demographic data such as age, sex, occupation, and location. All included patients were subjected to complete history, physical examination, comorbidities, electrocardiogram findings, and laboratory results. Laboratory results included lipid profile, PT, INR, PTT, CBC, troponin, LDH, liver, and renal function tests.

\section{Statistical Analysis}

Data were verified, entered into PC, and analyzed using SPSS version 24.0. The Continuous data were analyzed using measures of central tendency, while categorical data were described in percent (\%). For determining the associations between the variables Chi-square test, Fischer exact test, and Likelihood ratio were primarily used. The odds ratio was used as the outcome measure of association. Multiple logistic regression analysis was used to study the predictors of the dependent variable (acute coronary syndrome diagnosis).

\section{RESULTS}

There were 124 patients with (ACS) versus 91 hospital-based control patients without ACS. The majority of participants in the two groups were males $(80 \%)$. Their age ranged from 18 to 95 years old with a mean age of $53.9 \pm 13.6$ years. $(86.5 \%)$ of them were above 40 years old. There were no statistical differences between the study group and control group using the independent student t-test Table-1.

Table-1: The mean age of the study group (cases) and the control group

\begin{tabular}{|l|l|l|l|l|}
\hline Participant & $\mathbf{N}(\boldsymbol{\%})$ & Mean \pm SD & t value & P. value \\
\hline Cases & 124 & $54.8 \pm 11,6$ & & 0.132 \\
\hline Controls & 91 & $15,9 \pm 15,9$ & 1.513 & \\
\hline
\end{tabular}

Risk factors and characteristic behavior of both groups were examined and compared. The result showed that hypertension was more frequent in the study group than the control group $(71.6 \%)$ versus 
$(28.4 \%)(\mathrm{p}=0.005 \%)$. Additionally, Khat chewing was more prevalent among the cases than the control group $(64.4 \%)$ versus $(35.6 \%)$ with P value $(0.001)$. Smoking was more prevalent among ACS than the control group amounting to reach statistical significance with P-value 0.053. However, diabetes mellitus status failed to achieve statistical significance between ACS cases and the control group Table-2.

Table-2: Risk Factors associated with ACS compared to control group

\begin{tabular}{|l|l|l|l|l|}
\hline Factor & Cases & Controls & $\boldsymbol{x}^{\mathbf{2}}$ & p. value \\
\hline $\begin{array}{l}\text { Hypertension } \\
\text { Nypertensive }\end{array}$ & $48(71.6 \%)$ & $19(28.4 \%)$ & 7.8 & $0.005^{*}$ \\
\hline $\begin{array}{l}\text { Khat chewing } \\
\text { Chews Khat } \\
\text { Doesn't chew Khat }\end{array}$ & $103(64.4 \%)$ & $57(35.6 \%)$ & 11.5 & $0.001^{*}$ \\
\hline $\begin{array}{l}\text { Gender } \\
\text { Male }\end{array}$ & $105(61 \%)$ & $67(39 \%)$ & 4.1 & $0.045^{*}$ \\
Female & $19(44.2 \%)$ & $24(55.8 \%)$ & & \\
\hline $\begin{array}{l}\text { Smoking } \\
\text { Smoke }\end{array}$ & $90(59.6 \%)$ & $61(40.4 \%)$ & 3.73 & 0.053 \\
Non smoke & $34(\%)$ & $30(\%)$ & & \\
\hline $\begin{array}{l}\text { Diabetes (DM) } \\
\text { Has DM }\end{array}$ & $40(64.5 \%)$ & $22(35.5 \%)$ & 1.67 & 0.196 \\
No DM & $84(54.9 \%)$ & $69(45.1 \%)$ & & \\
\hline
\end{tabular}

Variables that showed statistically significant association using the Chi-square test, were further analyzed for possible confounding using multiple logistic regression analysis to obtain factors predicting ACS. The prediction models and the calculated adjusted odds ratios (AOR), table (3). In comparison to normotensive patients, the odds of having hypertension were 3.32 times greater among cases than controls. Similarly, the odds of being Khat chewer were 3.1 times greater among cases than controls. i.e. patients who had hypertension and/or chewed Khat had a higher risk of developing ACS.

Table-3: The prediction models and the calculated adjusted odds ratios (AOR)

\begin{tabular}{|l|l|l|l|l|l|l|l|}
\hline Predictor & B & S.E & Wald & p. val & AOR & \multicolumn{2}{|c|}{ 95 \% CI } \\
\cline { 5 - 8 } & 1.17 & 0.401 & 8.54 & $0.003^{*}$ & 3.32 & 1.49 & 7.07 \\
\hline $\begin{array}{l}\text { Blood pressure } \\
\text { Hypertensive } \\
\text { Normotensive }\end{array}$ & & & & & & & \\
\hline $\begin{array}{l}\text { Khat chewing } \\
\begin{array}{l}\text { Chews Khat } \\
\text { [Doesn't chew Khat }\end{array}\end{array}$ & 1.14 & 0.533 & 4.59 & $0.032^{*}$ & 3.1 & 1.1 & 8.9 \\
\hline
\end{tabular}

AOR: adjusted odds ratio, CI: confidence interval, []: reference category, * significant at p<0.05.

The lipid profile of both groups is shown in Table-4. It is obvious that total cholesterol, triglycerides, and low-density lipoproteins were higher among ACS cases than the control group with significant differences $\mathrm{P}$-value of $<0.05$. On the other hand, high-density lipoproteins did not differ largely between cases and control and there was no statistically significant difference in the HDL mean between the two groups.

Table-4: Lipid profile among cases and controls

\begin{tabular}{|l|l|l|l|l|l|}
\hline \multirow{2}{*}{ Lipid } & Cases & Controls & MD & T & P. value \\
\cline { 2 - 3 } & Mean \pm SD $(\mathbf{m g} / \mathbf{d l})$ & & & \\
\hline Total cholesterol & $163.5 \pm 43.8$ & $110.8 \pm 41.5$ & 52.7 & 4.35 & $<0.001^{*}$ \\
\hline Triglyceride & $153.2 \pm 66.2$ & $107.1 \pm 52.8$ & 46.2 & 2.6 & $0.012^{*}$ \\
\hline LDL & $110.4 \pm 25.5$ & $70.6 \pm 33.6$ & 39.8 & 3.01 & $0.006^{*}$ \\
\hline HDL & $34.8 \pm 10.2$ & $30.2 \pm 10.2$ & 4.6 & 1.01 & 0.32 \\
\hline $\begin{array}{l}\text { Mean difference tested by independent t-test. t: t-value, SD: standard deviation. } \\
\text { * Significant. }\end{array}$
\end{tabular}

Of 124 cases admitted wit ACS 9 patients (7.3 $\%)$ died in CCU. While $115(92.7 \%)$ were transferred to ward with good condition. On the other hand, 27 in control patients $(29.7 \%)$ died and $64(70.3 \%)$ were transferred to ward with good condition. This differences in mortality proportions were statistically significant. 


\section{DISCUSSION}

The majority of our patients presented with ACS were males $(80 \%)$, most of them (86.5\%) were 40 years old or above. Our findings are consistent with most studies conducted in Yemen in which the mean age of patients diagnosed with ACS ranged between 55.3 years to 56.8 years [16-18]. However, the incidence of ACS in the elderly is expected to rise due to improvements in prior ACS treatment in an aging population [19].

Regarding risk factors, we found that systemic hypertension is one of the major risk factors which is extensively prevalent in patients with ACS. It was known that increase blood pressure and uncontrolled hypertension can lead to endothelial dysfunction, increase the permeability of intima, left ventricular hypertrophy, and ultimately ischemic heart diseases with acute coronary syndrome [16-19].

Hypertension is also, associated with accelerated atherosclerosis, which contributes to the progression of myocardial infarction [20].

The unique finding in this study was that khat chewers were more venerable to ACS. Their risk to develop ACS was 3.1 times greater than the control group. This makes khat as an independent risk factor for the development of the acute coronary syndrome. Previously studied in Yemen found that Khat was a predisposing factor for heart ischemia and heart failure $[17,21]$.

In this study Lipid profiles such as total cholesterol, triglycerides, and low-density lipoproteins were higher among ACS cases than the control group. These findings were reported by studies done regionally and internationally [22-24]. Studies have shown that dyslipidemia was one of the prominent risk factors with ACS [25]. The higher the lipids the more severe it was the atherosclerosis [23]. A recent study from Brazil has reported that the main risk factors were arterial hypertension (68\%), smoking (67\%), and dyslipidemia $(43 \%)$ [26].

It was worth to mentioning that in this study diabetes, and smoking was prevalent among ACS. But they failed to achieve statistically significant. This finding may be related to the type of study design where, our control group was hospital-based (patients admitted to CCU) with a high prevalence of diabetes and probably smoking habit, making a determination of a difference of these factors were unsatisfied, yet, such a defect can be solved in future studies through using population controls or adapting a cohort prospective study design.

The same draw note can be recognized in the mortality rate we found the mortality rate in the control group was higher than the control group. That was because our control group was patients admitted into (CCU) because they had critical disease most of them suffered from multi-organ damages.

\section{CONCLUSION}

Preventable risk factors were the major factors for ACS. Health education and prevention program is mandatory for avoiding risk factors associated with ACS. Such a program may be used to decrease the occurring of ACS and reduced the morbidity and mortality of cardiovascular diseases in Yemen.

\section{RECOMMENDATION}

It is crucial to make an early and accurate diagnosis of ACS with risk stratification to guide therapy accordingly. It is necessary to provide training and prevention to prevent further cardiovascular disease through the educational class, mass media, and cyberspace in order to raise the level of awareness of people and reduce cardiovascular diseases. Countrywide studies related to cardiovascular diseases particularly ACS and locally risk factors are needed.

\section{ACKNOWLEDGMENT}

We Acknowledgment all responsibilities the authors would like to thank Dr. Ali Ahmed Al-Zaazaai M.Sc. clinical pharmacy from Wenzhou University, Wenzhou Zhejiang province PR China and products specialist with Al-Jabal Group of Company in Yemen who revision of the manuscript for an important intellectual content, and publication. The research team thanks all patients for their co-operation.

\section{Authors' Contribution}

Dr. Ahmed Kaid Salem, Dr. Nouradden Aljaber, Dr. Akram Al-Haj, Dr. Khairallah Abdulah AlMatari, Prof Amin Ablrub, study concept and design, data acquisition, interpretation; manuscript drafting, study supervision, the idea of the manuscript, collection, analysis, writing and literature review by them.

Conflict of Interests: The authors declared that there were no conflicts of interest arising in the process of this study.

\section{FUNDING}

This research received for publication a specific grant from Hetero pharmaceutical organization engaged in the development, manufacturing and marketing of high-quality Chemical and Biologic Drugs like Neoclopid 75mg, Amlosin 5mg, 10mg, OLMETEROH, AND OLMETERO 20MG, 40MG.

\section{REFERENCES}

1. Teich, V., Piha, T., Fahham, L., Squiassi, H. B., Paloni, E. D. M., Miranda, P., \& Araújo, D. V. (2015). Acute coronary syndrome treatment costs from the perspective of the supplementary health 
system. Arquivos brasileiros de cardiologia, 105(4), 339-344.

2. European Hospital Morbidity Database http://data.euro.who.int/ hmdb/index.php.

3. Roger, V. L., Go, A. S., \& Lloyd-Jones, D. M. (2011). Heart disease and stroke statistics update. Circulation, 123:e18-209.

4. Murray, C. J., \& Lopez, A. D. (1997). Alternative projections of mortality and disability by cause 1990 - 2020: Global burden of disease study. Lancet, 349:1498 -1504.

5. Thompson, A., Gao, P., Orfei, L., Watson, S., Di, E. A., Kaptoge, S., ... \& Hofman, A. (2010). Lipoprotein-associated phospholipase A (2) and risk of coronary disease, stroke, and mortality: collaborative analysis of 32 prospective studies. Lancet, 375(9725): 1536-1544.

6. Kones, R. (2011). Primary prevention of coronary heart disease: integration of new data, evolving views, revised goals, and role of rosuvastatin in management. A comprehensive survey. Drug design, development and therapy, 5, 325-380.

7. Egred, M., Viswanathan, G., \& Davis, G. K. (2005). Myocardial infarction in young adults. Postgraduate medical journal,81(962), 741-745.

8. Ahmed, E., El-Menyar, A., Singh, R., Al Binali, H. A., \& Al Suwaidi, J. (2012). Effect of age on clinical presentation and outcome of patients hospitalized with acute coronary syndrome: a 20year registry in a middle eastern country. The open cardiovascular medicine journal, 6, 60 .

9. Schoenenberger, A. W., Radovanovic, D., Stauffer, J. C., Windecker, S., Urban, P., Niedermaier, G., ... \& AMIS Plus Investigators. (2011). Acute coronary syndromes in young patients: presentation, treatment and outcome. International journal of cardiology, 148(3), 300-304.

10. Doughty, M., Mehta, R., Bruckman, D., Das, S., Karavite, D., Tsai, T., \& Eagle, K. (2002). Acute myocardial infarction in the young-The University of Michigan experience. American heart journal, 143(1), 56-62.

11. Desai, M. M., Stauffer, B. D., Feringa, H. H., \& Schreiner, G. C. (2009). Statistical models and patient predictors of readmission for acute myocardial infarction: a systematic review. Circulation: Cardiovascular Quality and Outcomes, 2(5), 500-507.

12. Johnston, S. S., Curkendall, S., Makenbaeva, D., Mozaffari, E., Goetzel, R., Burton, W., \& Maclean, R. (2011). The direct and indirect cost burden of acutecoronary syndrome. Journal of occupational and environmental medicine, 53(1), 2-7.

13. Omran, A. R. (1971). The epidemiologic transition: a theory of the epidemiology of population change. Milbank Mem Fund $Q$. 49(4):509-538.
14. Fernandez-Berges, D., Felix-Redondo, F. J., Lozano, L., Perez-Castan, J. F., Sanz, H., Cabrera, A. D. L., ... \& Alvarez-Palacios, P. (2011). Prevalence of metabolic syndrome estimated with the new World Health Organization recommendations. The HERMEX study. Gaceta sanitaria, 25(6), 519-524.

15. de León Cabrera, A., Rodríguez, C. P. M., Almeida, D. G., Domínguez, S. C., Aguirre, A. J., Brito, B. D., ... \& Pérez, L. M. (2008). Presentation of the" CDC de Canarias" cohort: objectives, design and preliminary results. Revista espanola de salud publica, 82(5), 519-534.

16. Al-Huthi, M. A., Raja'a, Y. A., Al-Noami, M., \& Rahman, A. R. A. (2006). Prevalence of coronary risk factors, clinical presentation, and complications in acute coronary syndrome patients living at high vs low altitudes in Yemen. Medscape General Medicine, 8(4), 28.

17. Al-Motarreb, A., Al-Kebsi, M., Al-Adhi, B., \& Broadley, K. J. (2002). Khat chewing and acute myocardial infarction. Heart, 87(3), 279-280.

18. Ahmed, A. M., Abdulwahab, A. M., Hesham, A. F., \& Nawar, W. (2013). Clinical presentation, management and outcome of acute coronary syndrome in Yemen: data from GULF RACE-2 Registry. Heart views: the official journal of the Gulf Heart Association, 14(4), 159.

19. Alexander, K. P., Roe, M. T., Chen, A. Y., Lytle, B. L., Pollack, C. V., Foody, J. M., ... \& Peterson, E. D. (2005). Evolution in cardiovascular care for elderly patients with non-ST-segment elevation acute coronary syndromes: results from the CRUSADE National Quality Improvement Initiative. Journal of the American College of Cardiology, 46(8), 1479-1487.

20. Picariello, C., Lazzeri, C., Attana, P., Chiostri, M., Gensini, G. F., \& Valente, S. (2011). The impact of hypertension on patients with acute coronary syndromes. International journal of hypertension, 2011.

21. Ali, W. M., Zubaid, M., Al-Motarreb, A., Singh, R., Al-Shereiqi, S. Z., Shehab, A., ... \& Al Suwaidi, J. (2010, November). Association of khat chewing with increased risk of stroke and death in patients presenting with acute coronary syndrome. In Mayo Clinic Proceedings (Vol. 85, No. 11, pp. 974-980). Elsevier.

22. Alhassan, S. M., Ahmed, H. G., Almutlaq, B. A., Alanqari, A. A., \& Alshammari, R. K. (2017). Risk Factors Associated with Acute Coronary Syndrome in Northern Saudi Arabia. Search of a Perfect Outfit. J Cardiol Curr Res, 8(3), 00281.

23. Penalva, R. A., Huoya, M. O., Correia, L. C., Feitosa, G. S., \& Ladeia, A. M. T. (2008). Lipid profile and severity of atherosclerotic disease in acute coronary syndrome. Arq Bras Cardiol, 90(1), 24-29.

24. Faiza, A., \& Khaled, A. (2019). High-Density Lipoprotein (HDL) Cholesterol Level among 
Patients with Acute Coronary Syndrome, Admitted to Coronary Unit in Kuwait University Hospital 2015-2017. Int J Cardiovasc Res, 8:3.

25. Abdelaziz, A., \& Fawzy, M. (2014). Prevalence and Pattern of Dyslipidemia In Acute Coronary Syndrome Patients Admitted to Medical Intensive Care Unit in Zagazig University Hospital, Egypt. Zagazig University Medical Journal, 20(3),
$1-10$.

26. Soeiro, A. D. M., Fernandes, F. L., Soeiro, M. C. F. D. A., Serrano Jr, C. V., \& Oliveira Jr, M. T. D. (2015). Clinical characteristics and long-term progression of young patients with acute coronary syndrome in Brazil. Einstein (Sao Paulo), 13(3), 370-375. 